\title{
BRPKM
}

Buletin Riset Psikologi dan Kesehatan Mental

http://e-journal.unair.ac.id/index.php/BRPKM

e-ISSN: 2776-1851

ARTIKEL PENELITIAN

\section{Pengaruh Resiliensi terhadap Work Engagement pada Guru}

\author{
NA'IMATUS SILIYAH \& CHOLICHUL HADI* \\ Fakultas Psikologi Universitas Airlangga
}

\begin{abstract}
ABSTRAK
Penelitian ini bertujuan untuk mengukur aspek resiliensi dan work engagement pada guru. Sampel penelitian ini merupakan seorang guru dengan jumlah 74 orang. Pengumpulan data dilakukan dengan menggunakan metode survei. Penulis menggunakan alat ukur Utrecht Work Engagement Scale-17 (UWES-17) dan Connor Davidson Resilience Scale (CD-RISC). Analisis data dilakukan dengan teknik regresi sederhana menggunakan perangkat lunak Jamovi 1.6.23 for Windows. Hasil penelitian menunjukkan adanya pengaruh resiliensi terhadap work engagement sebesar $(F(1,72)=16,8 ; p<0,01$; $R^{2}=0.189$ ). Artinya, tingkat resiliensi yang dimiliki individu dapat memprediksikan dan menggambarkan intensi work engagement sebesar 18,9\%.
\end{abstract}

Kata kunci: guru, resiliensi, work engagement

\section{ABSTRACT}

This research aims to measure the psychological resilience aspect towards work engagement on teacher. The sample of this research is a teacher totaling 74 people. Data collection was carried out using the survey method. The author uses the Utrecht Work Engagement Scale-17 (UWES-17) and Connor Davidson Resilience Scale (CD-RISC) measuring instruments. Data analysis was performed using a simple regression technique using Jamovi 1.6.23 for Windows software. The results shows that psychological resilience clearly affected the work engagement $\left(F(1.72)=16.8 ; p<0.01 ; R^{2}=0.189\right)$. Definitively, the psychological resilience rate from a person can predict and depict the work engagement intention to reach $18,9 \%$.

Keywords: resilience, teacher, work engagement

Buletin Penelitian Psikologi dan Kesehatan Mental (BRPKM), 2021, Vol. 1(2), 1152-1160

*Alamat korespondensi: Fakultas Psikologi Universitas Airlangga, Kampus B Universitas Airlangga Jalan Airlangga 4-6 Surabaya 60286. Surel: cholichul.hadi@psikologi.unair.ac.id

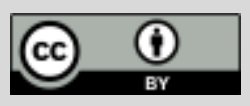

Naskah ini merupakan naskah dengan akses terbuka dibawah ketentuan the Creative Common Attribution License (CC-BY-4.0) (http://creativecommons.org/licenses/by/4.0), sehingga penggunaan, distribusi, reproduksi dalam media apapun atas artikel ini tidak dibatasi, selama sumber aslinya disitir dengan baik. 


\section{PENDAHULUAN}

Peran guru sebagai tenaga pendidik tidak bisa tergantikan bahkan oleh teknologi sekalipun. Hal ini terbukti pada kegiatan belajar mengajar saat ini yang telah dilakukan secara daring sebagai imbas dari penyebaran COVID-19 di Indonesia. Para staf pengajar dan siswa harus belajar dengan sistem pembelajaran yang berbeda dan menghadirkan permasalahan dan tantangan, dimulai dari permasalahan internet, kondisi psikososial staf pengajar dan siswa, disparitas kompetensi antar staf pengajar serta keterbatasan waktu orangtua dan wali murid mendampingi anak saat mengikuti pembelajaran jarak jauh (Makarim, 2021). Dilansir dari CNN Indonesia tentang Survei KPAI: Guru Tak Interaktif Selama Belajar Dari Rumah (n.d.) menunjukkan bahwa guru tidak interaktif selama kegiatan pembelajaran jarak jauh. Dari hasil tersebut menjelaskan, tidak ada proses kegiatan belajar mengajar selama kegiatan pembelajaran jarak jauh. Tercatat sebesar $79.9 \%$ peserta didik menyebutkan bahwa komunikasi yang terjadi dengan guru hanya sebatas menugaskan pekerjaan kepada siswa dan menagih hasilnya, tanpa ada kegiatan belajar mengajar yang disesuaikan dengan pembelajaran jarak jauh.

Penerapan pembelajaran jarak jauh yang ditetapkan oleh pemerintah hingga pro kontra pembukaan sekolah dengan sistem tatap muka berdampak kepada para pelaku pendidikan. Keputusan untuk melaksanakan kembali pembelajaran tatap muka juga menimbulkan pro dan kontra di kalangan orangtua dan guru, kebijakan membuka sekolah tatap muka kembali harus mempertimbangkan keselamatan para staf pengajar dan peserta didik. Pasalnya, angka pasien positif COVID-19 terus melonjak secara signifikan (Pratiwi, 2021). Guru yang bekerja selama proses pembelajaran jarak jauk melaporkan merasa stres dan bahkan berpikir untuk berhenti dari profesinya. Pendapat ini sesuai dengan hasil survei The State Teachers Union, sebesar 29\% guru berpikir untuk berhenti bekerja selama COVID-19, guru harus mengajar murid dengan cara yang berbeda selama pandemi COVID-19 akibatnya banyak guru tidak bekerja sesuai jam kerja dan berencana berhenti bekerja (Verges, 2020).

Mempertimbangkan fungsi dan tugas yang harus dipenuhi oleh tenaga pendidik, seorang tenaga pendidik dituntut untuk bekerja maksimal meskipun dengan banyak tantangan, terlebih lagi pada situasi COVID-19. Profesi guru membutuhkan kepuasan, antusias dan keterlibatan penuh pada setiap pekerjaan untuk dapat memberikan kinerja terbaiknya bagi organisasi pendidikan tersebut (Roberts \& Davenport, 2002). Karakteristik tersebut merupakan karakteristik dari individu yang merasa engaged terhadap pekerjaannya. Individu atau karyawan yang merasa engaged dengan pekerjaannya, selain memiliki energi dan semangat yang tinggi, mereka juga akan terhubung dengan aktivitas pekerjaannya dan mampu menerima dengan baik tuntutan dari pekerjaan mereka (Schaufeli dkk., 2002).

Profesi guru merupakan pekerjaan yang menitikberatkan kualitas pelayanan kepada peserta didik, sehingga individu yang bekerja sebagai guru dituntut untuk memiliki work engagement yang tinggi (Smulder, 2006 dalam Schaufeli, 2011). Work engagement didefinisikan sebagai aspek emosi positif yang dikarakteristikkan dalam tiga dimensi yaitu vigor, dedication, dan absorption. Dimensi vigor atau semangat ditunjukkan pada individu yang bergairah, tekun dan memiliki kekuatan mental dalam melakukan pekerjaan yang diberikan meskipun menemui kendala di dalamnya (Schaufeli \& Bakker, 2004). Pada dimensi dedication atau dedikasi yang ditunjukkan dengan keterlibatan individu pada pekerjaannya sehingga menimbulkan kesan yang bermakna terhadap pekerjaan, dan merasa antusias serta tertantang dengan beban pekerjaan yang ada (Schaufeli \& Bakker, 2004). Terakhir, pada dimensi absorption yang melihat mengenai konsentrasi yang dimiliki oleh individu saat bekerja dan tidak mudah memisahkan diri dengan pekerjaan sehingga tidak segan meluangkan waktu yang lebih banyak untuk mengerjakan pekerjaannya (Schaufeli \& Bakker, 2004). 
Merujuk pada penelitian (Bakker \& Demerouti, 2008) yang menjelaskan penyebab dari work engagement, yaitu job resources dan personal resources. Job resources merupakan aspek yang bersumber pada pekerjaan yang diartikan sebagai hal yang meliputi keadaan lingkungan di sekitar individu seperti lingkungan sosial ataupun pekerjaannya tersebut (Bakker \& Demerouti, 2008). Sedangkan personal resources merupakan evaluasi diri yang positif, seperti self-efficacy, optimis, harapan dan resiliensi yang menunjukkan kemampuan individu memprediksi bagaimana tujuannya, motivasi, performa, pekerjaan dan kepuasan hidup, serta hasil yang diinginkan (Bakker \& Demerouti, 2008). Personal resource yang dimiliki seorang guru, terutama resiliensi sangat berguna untuk meningkatkan work engagement pada pekerjaannya (Sweetman \& Luthans, 2010).

Kondisi kerja guru dapat berubah dengan cara yang tidak terduga dan tergantung pada bagaimana menyikapi perubahan yang terjadi, guru akan menunjukkan ketahanan atau tidak mampu mengatasi perubahan (Wingerden \& Poell, 2019). Adanya kondisi yang tidak dapat diprediksi, maka dibutuhkan resiliensi yang berguna agar pekerja tersebut tetap bertahan pada organisasinya dan mampu melewati proses perubahan dengan baik (Patterson dkk., 2004). Selain itu, individu yang memiliki resiliensi tinggi cenderung mampu melakukan koping dan menyesuaikan diri dengan baik ketika menghadapi kesulitan, sehingga berdampak positif terhadap meningkatnya work engagement pada karyawan (Wang dkk., 2017).

Resiliensi adalah kualitas diri pada individu tersebut yang berguna untuk mengembangkan kemampuannya dalam mengatasi kesulitan yang terjadi pada hidupnya (Connor \& Davidson, 2003). Kekuatan resiliensi yang dimiliki individu dapat memengaruhi kemampuan dalam menyesuaikan diri dan beradaptasi terhadap peristiwa berat yang terjadi serta tetap bertahan walaupun harus berhadapan dengan masalah ataupun trauma yang pernah terjadi pada hidupnya (Reivich \& Shatte, 2002). Luthans \& Youssef (2004) menyebutkan bahwa resiliensi di tempat kerja juga mencakup dimensi proaktif yang dapat menciptakan keberhasilan tanpa merasa ada ancaman. Resiliensi mampu membuat karyawan lebih kreatif dan fleksibel, namun diimbangi dengan nilai etika dan kepercayaan diri yang kuat untuk mencapai tujuan yang bermakna (Luthans \& Youssef, 2004).

Individu dalam organisasi yang memiliki resiliensi memandang kesulitan yang terjadi menjadi sebuah kesempatan untuk berkembang dan menjadikan dirinya semangat untuk menyelesaikan tugas pekerjaannya dengan baik walaupun dengan kondisi yang menegangkan (Maddi \& Khoshaba, 2005). Resiliensi tidak hanya seputar kemampuan yang dimiliki individu dalam beradaptasi pada kondisi yang sulit, namun juga kekuatan individu dalam memperjuangkan kondisi kesehatannya agar dalam proses menyesuaikan dengan lingkungan tidak maladaptif (Siebert, 2005). Berbeda dengan individu yang tidak memiliki resiliensi, individu akan bertindak secara kaku, tidak sesuai, dan bertindak maladaptif ketika menghadapi kondisi yang sulit (Siebert, 2005).

Dari penjelasan yang telah diuraikan sebelumnya, peneliti memutuskan meneliti tentang pengaruh resiliensi terhadap work engagement guru. Sementara, penelitian ini bertujuan menguji pengaruh resiliensi terhadap work engagement pada guru. Sementara itu, hipotesis kerja yaitu resiliensi berpengaruh terhadap work engagement pada guru. 


\section{Desain Penelitian}

\section{METODE}

Penelitian ini menggunakan pendekatan kuantitatif-survei. Penelitian ini menggunakan data bentuk angka dan dilakukan proses pengujian hipotesis, analisa statistik, tabel dan diagram serta menggunakan prosedur yang telah terstandar (Neuman, 2014). Jenis penelitian ini adalah explanatory research yang bertujuan untuk mendapatkan hasil uji akurasi teori ataupun pertanyaan penelitian terdahulu. Pengumpulan data dilakukan dengan metode survei dengan media kuesioner yang dibagi menjadi tiga bagian, yaitu demografis, skala Connor Davidson Resilience Scale (CD-RISC) untuk mengukur resiliensi dan skala Utrecht Work Engagement Scale-17 (UWES-17) untuk mengukur work engagement. Peneliti memilih metode tersebut karena sesuai dengan tujuan penelitian yaitu untuk menjelaskan pengaruh dan menguji hipotesis dari suatu fenomena yang diangkat.

\section{Partisipan}

Partisipan penelitian ini adalah guru yang bekerja di SMAN 1 Bangil. Teknik pengambilan sampel dengan total sampling/sampling jenuh. Total Sampling merupakan cara mengambil sampel di mana seluruh anggota populasi menjadi sampel penelitian tanpa proses seleksi atau eliminasi (Sugiyono, 2013). Penggunaan total sampling ini mempertimbangkan anggota populasi yang jumlahnya sedikit dan dapat dijangkau oleh peneliti. Jumlah sampel pada penelitian ini yaitu 74 guru yang terdiri dari guru PNS/Non PNS. Sebelum mengisi survei, partisipan diminta untuk membaca pernyataan yang diberikan untuk memastikan bahwa partisipan setuju untuk berpartisipasi dalam penelitian ini.

Penelitian melibatkan 74 partisipan $\left(M_{\text {usia }}=43,1 ; S D_{\text {usia }}=12,6\right)$ yang bekerja sebagai guru di SMA Negeri 1 Bangil. Lama bekerja partisipan variatif, yaitu 9 orang (12.2\%) bekerja selama 1-2 tahun, 11 orang (14.8\%) bekerja selama 3-5 tahun, 9 orang (12.2\%) bekerja selama 6-10 tahun, 17 orang (23\%) bekerja selama 11 -20 tahun, dan 28 orang (37.8\%) telah bekerja selama lebih dari 20 tahun.

\section{Pengukuran}

Pengukuran variabel resiliensi dalam penelitian ini menggunakan skala yang disusun (Connor \& Davidson, 2003) yaitu Connor Davidson Resilience Scale (CD-RISC) dan diadaptasi ke dalam Bahasa Indonesia oleh (Fatmawati, 2016). Terdapat 25 aitem dan diukur menggunakan 5 skala likert ( $0=$ "tidak pernah", 4="sering"). Sedangkan untuk mengukur variabel work engagement menggunakan skala yang dikembangkan (Schaufeli \& Bakker, 2004) yaitu Utrecht Work Engagement scale-17 (UWES-17) dan ditranslasi (Permatasari, 2018). Terdapat 17 aitem dan diukur menggunakan 7 skala likert $(0=$ "tidak pernah", 6="selalu").

Penelitian ini memakai validitas isi dengan bantuan professional judgement yang dianggap memiliki keahlian sesuai dengan bidang penelitian ini. Pada penelitian ini, validitas alat ukur CD-RISC dan UWES17 merujuk pada penelitian sebelumnya terhadap masing-masing alat ukur. Keduanya menggunakan validitas isi dan menguji alat ukur CD-RISC dan UWES-17 dengan professional judgement. Sedangkan reliabilitas yang digunakan berasal dari koefisien Cronbach's alpha. Berdasarkan penelitian yang dilakukan sebelumnya, reliabilitas alat ukur CD-RISC adalah $\alpha=0.915$ dan reliabilitas alat ukur UWES17 yaitu $\alpha=0.925$. Jika dilihat dari data yang telah dikumpulkan penulis, hasil analisis reliabilitas skala CD-RISC memiliki koefisien reliabilitas sebesar $\alpha=0.926$ dan skala UWES-17 sebesar $\alpha=0.910$.

\section{Analisis Data}


Analisis data yang dilakukan adalah uji regresi sederhana. Hal ini dikarenakan tujuan penelitian adalah menguji secara empiris apakah terdapat pengaruh resiliensi terhadap work engagement pada guru. Sebelum dilakukan uji regresi sederhana, dilakukan uji asumsi seperti uji kenormalitasan data, uji linearitas data dan uji homoskedastisitas. Analisis statistik menggunakan perangkat lunakJamovi 1.6.23 for Windows.

\section{HASIL PENELITIAN}

\section{Analisis Deskriptif}

Hasil analisis deskriptif statistik pada 74 partisipan yang menunjukkan nilai variabel resiliensi dan work engagement. Pada variabel resiliensi diketahui diketahui (Min=65; $M a x=100 ; N=74 ; M=81,9 ; S D=8,94)$. Sementara pada variabel work engagement diketahui (Min=44; $M a x=102 ; N=74 ; M=80,3 ; S D=12,3$ ). Partisipan penelitian ini mendominasi work engagement dengan kategorisasi sedang sebesar 53 (71,6\%), sebesar $11(14,9 \%)$ partisipan berada kategorisasi tinggi, dan kategori rendah sebanyak 10 orang $(13,5 \%)$.

\section{Uji Asumsi}

Uji asumsi menggunakan nilai skewness dan kurtosis. Nilai skewness sebesar -0,698 dan kurtosis 0,249. Sedangkan pada variabel resiliensi, nilai skewness sebesar 0,423 dan kurtosis -0,706. Hasil uji normalitas melalui skewness dan kurtosis menunjukkan bahwa data pada variabel resiliensi dan work engagement berdistribusi normal karena mendekati angka 0, sehingga asumsi normalitas data telah terpenuhi. Selanjutnya, uji linearitas menggunakan scatterplot. Jika persebaran titik pada scatterplot tidak membentuk suatu pola tertentu, maka hubungan antara dua variabel dapat dikatakan linear. Pada penelitian ini, hubungan kedua variabel cukup linear dimana tingginya resiliensi diikuti tingginya work engagement.

\section{Uji Regresi Sederhana}

Hasil uji regresi sederhana menghasilkan $\left(F(1,72)=16,8 ; p<0,01 ; R^{2}=0.189\right)$. Nilai ini menunjukkan tingkat resiliensi pada individu dapat memprediksikan dan menggambarkan intensi work engagement sebesar 18.9\%. Variabel resiliensi menghasilkan $(B=0,598 ; 95 \% ; S E=0,435 ; t=4,10 ; p<0,01)$ yang menunjukkan nilai positif, sehingga ketika tingkat resiliensi yang dimiliki individu meningkat akan memengaruhi tingkat work engagement, dan sebaliknya apabila resiliensi yang dimiliki individu rendah akan berdampak pada penurunan work engagement pada individu tersebut.

\section{DISKUSI}

Berdasarkan analisis yang telah dilakukan, ditemukan bahwa variabel resiliensi memiliki pengaruh terhadap variabel work engagement. Hasilnya, nilai dari variabel resiliensi memprediksi nilai dari variabel work engagement $\left(F(1,72)=16,8 ; p<0,01 ; R^{2}=0.189\right)$. Artinya, tingkat resiliensi yang dimiliki individu dapat memprediksikan dan menggambarkan sebesar $18.9 \%$ intensi work engagement. Persamaan garis yang diperoleh yaitu $Y^{\prime}=31.380+(0.598) \mathrm{X}+$ e. Dari persamaan tersebut, resiliensi berpengaruh positif terhadap work engagement. Artinya, setiap peningkatan pada variabel resiliensi, terdapat peningkatan pula pada variabel work engagement.

Penelitian ini menemukan bahwa terdapat pengaruh variabel resiliensi terhadap work engagement pada guru. Sejalan dengan Ojo dkk. (2021) yang melakukan penelitian mengenai pentingnya resiliensi

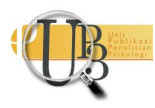


dalam mendukung individu untuk mengatasi dan bangkit kembali dari krisis dan situasi tak terduga seperti pandemi COVID-19. Penelitian ini mengungkapkan bahwa terdapat dampak signifikan resiliensi terhadap work engagement karyawan. Individu yang resilien akan lebih mampu menganalisa, merespon, bahkan mengatasi lingkungan yang penuh dengan tantangan secara efektif (Villavicencio dkk., 2014). Hal ini juga didukung oleh Ugwu \& Amazue (2014) yang melakukan penelitian tentang resiliensi dan work engagement yang dilakukan di Nigeria dengan guru sebagai partisipan. Hasilnya menunjukkan bahwa resiliensi memiliki pengaruh work engagement secara signifikan. Resiliensi disebut sebagai salah satu cara untuk mengembalikan tenaga setelah mengalami keterpurukan dan kegagalan (Ugwu \& Amazue, 2014).

Penelitian selanjutnya, Mase \& Tyoktaa (2014) yang melakukan penelitian terhadap 202 petugas kesehatan dan hasilnya menyebutkan bahwa variabel resiliensi dan work engagement berhubungan secara signifikan. Apabila aspek resiliensinya tinggi, maka berdampak pada peningkatan keterlibatannya pada pekerjaan tersebut. Lebih lanjut, karyawan yang memiliki potensi untuk mempertahankan dan melewati situasi yang sulit pada organisasinya dengan baik cenderung engaged terhadap pekerjaan. Selaras dengan penelitian ini, Astika \& Saptoto (2016) juga menemukan hal yang sama, bahwa terdapat pengaruh di antara dua variabel tersebut. Individu dengan resiliensi yang tinggi memperlihatkan bagaimana beradaptasi dengan situasi yang berubah-ubah dan hal tersebut berakibat pada performa kerjanya yang baik (Astika \& Saptoto, 2016).

Resiliensi adalah salah satu anteseden dari work engagement. Individu yang memiliki resiliensi cenderung menunjukkan bahwa mampu menghargai dirinya dan berkeyakinan mampu mengelola tugas pekerjaan dengan baik serta termotivasi dengan tujuan yang telah ditetapkan, sehingga individu tersebut akan engaged dengan pekerjaannya (Luthans \& Youssef, 2004). Tingkat resiliensi yang dimiliki oleh individu mampu memengaruhi kemampuannya dalam pekerjaan, seperti kemampuan dalam menangani masalah yang terjadi, menanggapi tanda-tanda bahaya dengan tenang, memandang kehidupan dengan positif, beradaptasi pada perubahan yang terjadi serta memiliki ketahanan pada situasi sulit (Anisman, 2015).

Jika ditarik kesimpulan, resiliensi memengaruhi tingkat work engagement pada karyawan. Strumpfer (1990, dalam Tims \& Bakker, 2010) menyebutkan bahwa karyawan yang memiliki resiliensi dapat mengembangkan occupational self direction yang berarti mereka menggunakan inisiatif, pemikiran, dan pertimbangan secara independen dalam pekerjaan. Tentunya, hal ini sangat menunjang individu agar tetap sehat serta menghadapi stressor yang ada sebagai tantangan dan bukan sebagai tekanan yang tinggi. Individu dengan tingkat work engagement yang tinggi akan memperlihatkan kinerja terbaiknya, hal ini dilakukan sebab individu tersebut menikmati pekerjaannya (Bakker \& Leiter, 2010).

\section{SIMPULAN}

Penelitian ini menyimpulkan bahwa ada pengaruh resiliensi terhadap work engagement pada guru. Saran untuk penelitian selanjutnya, agar mempertimbangkan untuk melihat faktor-faktor internal yang ada pada dalam diri individu yang memengaruhi work engagement seperti self efficacy, hope dan optimism.

Hasil pada penelitian ini menemukan bahwa tingkat resiliensi yang dimiliki oleh guru berpengaruh terhadap work engagement guru. Maka perlu dilakukan pengembangan untuk meningkatkan resiliensi guru. Langkah yang dapat dilakukan pihak sekolah untuk meningkatkan resiliensi guru yaitu dengan mengasah strategi yang mendasari resiliensi. Misalnya, memberikan pelatihan tentang sikap positif 
yang harus dimiliki guru dalam menghadapi kesulitan kerjanya, memfokuskan pada core value yang dimiliki guru, berani mengambil keputusan dalam menghadapi kesulitan, menyiapkan kondisi individu yang sesuai dengan tuntutan kerjanya, dan mengembangkan sikap guru yang partisipatif dalam proses pembelajaran dan bertanggung jawab.

\section{UCAPAN TERIMAKASIH}

Terimakasih kepada Allah SWT, keluarga, saudara dan teman serta sahabat yang telah mendukung penulis selama proses penelitian. Terima kasih juga saya ucapkan kepada peneliti sebelumnya yang telah memberikan izin untuk pemakaian alat ukur resiliensi dan work engagement.

\section{DEKLARASI POTENSI TERJADINYA KONFLIK KEPENTINGAN}

Na'imatus Siliyah dan Cholichul Hadi tidak bekerja, menjadi konsultan, memiliki saham, atau menerima dana dari perusahaan atau organisasi manapun yang mungkin akan mengambil untung dari diterbitkannya naskah ini.

\section{PUSTAKA ACUAN}

Anisman, H. (2015). Stress and Your Health: From Vulnerability to Resilience. John Wiley \& Sons.

Astika, N. F. L., \& Saptoto, R. (2016). Peran Resiliensi dan Iklim Organisasi terhadap Work Engagement. Gajah Mada Journal of Psychology, 2(1), 38-47. https://doi.org/10.22146/gamajop.31868

Bakker, A. B., \& Demerouti, E. (2008). Towards a model of work engagement. Career Development International, 13(3), 209-223. https://doi.org/10.1108/13620430810870476

Bakker, A. B., \& Leiter, M. P. (2010). Work Engagement: A Handbook of Essential Theory and Research. Psychology Press.

Connor, K. M., \& Davidson, J. R. T. (2003). Development of a new Resilience scale: The Connor-Davidson Resilience scale (CD-RISC). Depression and Anxiety, 18(2), 76-82. https://doi.org/10.1002/da.10113

Fatmawati, C. (2016). Hubungan antara Resiliensi dan Self efficacy dengan Work engagement pada Guru Tidak Tetap di Kecamatan Galis Pamekasan. Universitas Airlangga.

Luthans, F., \& Youssef, C. M. (2004). Human, social, and now positive psychological capital management: Investing in people for competitive advantage. Organizational Dynamics, 33(2), 143-160. https://doi.org/10.1016/j.orgdyn.2004.01.003

Maddi, S. R., \& Khoshaba, D. M. (2005). Resilience at Work: How to Succeed No Matter What Life Throws at You. American Management Assosiation (AMACOM).

Makarim, N. (2021). Panduan Penyelenggaraan Pembelajaran PAUDDIKDASMEN Masa Pandemi COVID19. Kementerian Pendidikan, Kebudayaan, Riset, dan Teknologi Kementerian Agama.

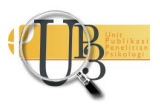


Mase, J. A., \& Tyoktaa, T. L. (2014). Resilience and Organizational Trust as Correlates of Work Engagement among Health Workers in Makurdi Metropolis. European Journal of Business and Management, 6(39), 86-94.

Neuman, W. L. (2014). Social Research Methods: Qualitative and Quantitative Approaches (7th ed). Pearson Education Limited.

Ojo, A. O., Fawehinmi, O., \& Yusliza, M. Y. (2021). Examining the Predictors of Resilience and Work Engagement during the COVID-19 Pandemic. Sustainabillity, 13(2902), 1-18.

Patterson, J., Collins, L., \& Abbott, G. (2004). A Study of Teacher Resilience in Urban Schools. Journal of Instructional Psychology, 31, 3-11.

Permatasari, F. (2018). Hubungan antara Job Insecurity (Ketidakamanan Kerja) dengan Work Engagement (Keterikatan Kerja) pada Guru Honorer SMA Negeri Di Surabaya. Universitas Airlangga.

Pratiwi, D. (2021). Pro Kontra Wacana Nadiem Mulai Sekolah Tatap Muka Juli 2021 Mendatang —News Liputan6.com. Retrieved July 18, 2021, from https://www.liputan6.com/news/read/4496741/pro-kontra-wacana-nadiem-mulai-sekolahtatap-muka-juli-2021-mendatang

Reivich, K., \& Shatte, A. (2002). The resilience factor: 7 essential skills for overcoming life's inevitable obstacles. Broadway Books.

Roberts, D. R., \& Davenport, T. O. (2002). Job engagement: Why it's important and how to improve It. Employment Relations Today, 29(3), 21-29. https://doi.org/10.1002/ERT.10048

Schaufeli, W. (2011). Work Engagement: What do we know? Int. OHP Workshop, Timisoara, December 2011.

Schaufeli, W., \& Bakker, A. (2004). Utrecht work engagement scale Preliminary Manual Version 1.1. Occupational Health Psychology Unit Utrecht University, December, 1-60. https://doi.org/10.1037/t01350-000

Schaufeli, W., Salanova, M., Gonzalez-Roma, V., \& Bakker, A. B. (2002). The Measurement Of Engagement and Burnout: A Two Sample Confirmatory Factor Analytic Approach. Journal of Happiness Studies, 3, 71-92. https://doi.org/10.1023/A:1015630930326

Siebert, A. (2005). The Resiliency Advantage: Master Change, Thrive Under Pressure, and Bounce Back from Setbacks. Berrett-Koehler Publishers.

Sugiyono. (2013). Metode Penelitian Kuantitatif, Kualitatif, dan R\&D. Alfabeta.

Survei KPAI: Guru Tak Interaktif selama Belajar dari Rumah. (n.d.). Retrieved July 18, 2021, from https://www.cnnindonesia.com/nasional/20200427160228-20-497716/survei-kpai-gurutak-interaktif-selama-belajar-dari-rumah 
Sweetman, D., \& Luthans, F. (2010). The power of positive psychology: Psychological capital and work engagement. In A. B. Bakker \& M. P. Leiter (Eds.), Work engagement: A handbook of essential theory and research (pp. 54-68). Psychology Press.

Tims, M., \& Bakker, A. B. (2010). Job Crafting: Towards a New Model of Individual Job Redesign. $S A$ Journal of Industrial Psychology, 36(2), 1-9.

Ugwu, F., \& Amazue, L. (2014). Psychological Ownership, Hope, Resilience and Employee Work Engagement behaviour among Teachers in Selected Mission Schools. European Journal of Business and Management, 6(10).

Verges, J. (2020). Union survey warns of MN teacher burnout, especially on hybrid schedules - Twin Cities. https://www.twincities.com/2020/10/12/union-survey-warns-of-mn-teacher-burnoutespecially-on-hybrid-schedules/

Villavicencio, E. A., Jurado, S. C., \& Valencia, A. C. (2014). WORK ENGAGEMENT AND OCCUPATIONAL BURNOUT: ITS RELATION TO ORGANIZATIONAL SOCIALIZATION AND PSYCHOLOGICAL RESILIENCE. Journal of Behavior, Health \& Social Issues, 6(2). https://doi.org/10.5460/jbhsi.v6.2.47026

Wang, Z., Li, C., \& Li, X. (2017). Resilience, Leadership and Work Engagement: The Mediating Role of Positive Affect. Social Indicators Research, 132(2), 699-708. https://doi.org/10.1007/s11205016-1306-5

Wingerden, J. V., \& Poell, R. F. (2019). Meaningful work and resilience among teachers: The mediating role of work engagement and job crafting. PLOS ONE, 14(9), e0222518. https://doi.org/10.1371/journal.pone.0222518 